\title{
Ferroelectrics
}

\section{Elastic and optical properties of sillenites: First principle calculations}

\author{
Husnu Koc, Selami Palaz, Sevket Simsek, Amirullah M. Mamedov \& Ekmel \\ Ozbay
}

To cite this article: Husnu Koc, Selami Palaz, Sevket Simsek, Amirullah M. Mamedov \& Ekmel Ozbay (2020) Elastic and optical properties of sillenites: First principle calculations, Ferroelectrics, 557:1, 98-104, DOI: 10.1080/00150193.2020.1713354

To link to this article: https://doi.org/10.1080/00150193.2020.1713354

曲 Published online: 07 Apr 2020.

Submit your article to this journal

Џ Article views: 55

Q View related articles $₫$

View Crossmark data 


\title{
Elastic and optical properties of sillenites: First principle calculations
}

\author{
Husnu Koc ${ }^{\mathrm{a}}$, Selami Palaz ${ }^{\mathrm{b}}$, Sevket Simsek ${ }^{c}$, Amirullah M. Mamedov ${ }^{\mathrm{d}, \mathrm{e}}$, and \\ Ekmel Ozbay ${ }^{\text {d }}$
}

${ }^{a}$ Department of Physics Faculty of Science and Letters, Siirt University, Siirt, Turkey; ${ }^{b}$ Department of Physics, Faculty of Science and Letters, Harran University, Sanlıurfa, Turkey; ${ }^{C}$ Department of Material Science and Engineering, Faculty of Engineering, Hakkari University, Turkey; ${ }^{\mathrm{d} N a n o t e c h n o l o g y}$ Research

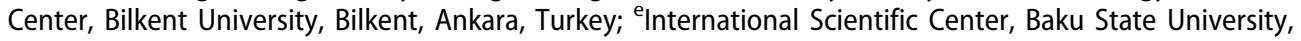
Baku, Azerbaijan

\begin{abstract}
In the present paper, we have investigated the electronic structure of some sillenites - $\mathrm{Bi}_{12} \mathrm{MO}_{20}(\mathrm{M}=\mathrm{Ti}, \mathrm{Ge}$, and $\mathrm{Si})$ compounds based on the density functional theory. The mechanical and optical properties of $\mathrm{Bi}_{12} \mathrm{MO}_{20}$ have also been computed. The second-order elastic constants have been calculated, and the other related quantities have also been estimated in the present work. The band gap trend in $\mathrm{Bi}_{12} \mathrm{MO}_{20}$ can be understood from the nature of their electronic structures. The obtained electronic band structure for all $\mathrm{Bi}_{12} \mathrm{MO}_{20}$ compounds is semiconductor in nature. Similar to other oxides, there is a pronounced hybridization of electronic states between M-site cations and anions in Bi12MO20. Based on the obtained electronic structures, we further calculate the frequency-dependent dielectric function and other optical functions.
\end{abstract}

\section{ARTICLE HISTORY}

Received 14 July 2019

Accepted 24 December 2019

\section{KEYWORDS}

ab initio calculation; electronic structure; mechanical properties; optical properties

\section{Introduction}

Individual dodecabismuth metal $\left(\mathrm{M}^{4+}=\mathrm{Ti}^{4+}, \mathrm{Ge}^{4+}, \mathrm{Si}^{4+}\right)$ oxides compounds $\left(\mathrm{Bi}_{12} \mathrm{MO}_{20}\right.$ - BMO) with a sillenite-type structure are formed as a result of interaction of bismuth oxide with oxides of elements that can be tetrahedrally coordinates by oxygen [1]. BMO crystals are isostructural to the metastable body-centered cubic phase $\Upsilon-\mathrm{Bi}_{2} \mathrm{O}_{3}$ have strong dielectric properties and are characterized by a variety of unusual physical effects (piezoelectric, elastic, electro- and elasto-optical, optical activity and photorefraction) and belong to the I23 space group, with no center of inversion. In BMO crystals tetrahedral positions of $\mathrm{M}$ ions can be statistically occupied by isomorphic mixture of $\mathrm{M}^{\mathrm{n}+}$ cations $(n=2-5)$ with strongly differing ionic radii, which leads to a wide class sillenites $[1,2]$. At the atomic level, the mechanisms of unusually wide isomorphism with respect to $\mathrm{M}$-cations in $\mathrm{BMO}$ crystal were considered in some earler investigations. It was shown that the bismuth-oxygen sublattice plays a decisive role in the existence of a wide class of isomorphic sillenite type compounds. Theoretical researches on BMO 
involve energy calculations, photcatalysis analysis of them, effect on pressure and comparative study of crystal structure structures of all three pure sillenites [1-5]. So far, the most properties of sillenites (structural, optical and electronic) have been studied experimentally [6-9]. First electronic structure results of the BMO have been discussed in $[10,11]$ by using local pseudopotential and $\mathrm{X} \alpha$ methods [12]. On the next step, some theoretical calculations of electronic structure and optical properties of BMO were calculated by using FP-LAPW method $[13,14]$. Neither of the above sited works has discussed the elastic properties of sillenites. Therefore, the first objective of our paper is to accurately determine elastic properties of BMO sillenites, as a first and necessary step toward the future investigation of the mechanical properties in these materials. To our knowledge, the elastic constants, Young's modulus, shear modulus, Poisson's ratio, sound velocities, Debye temperature have not been reported in detail for BMO so far. Our other objective is to determine electronic states and optical properties of sillenites in a wide energy region up to $30 \mathrm{eV}$ and gather all these theoretical data at one place. In this regard, we have conducted calculations of BMO crystals based on the DFT. Details of calculations are presented in Sections "Calculation details and structure optimization" and "Results and discussion"

\section{Calculation detail and structure optimization}

The crystal structure of the BMO's is body centered cubic (I23 space group) and the prototip crystal is a mineral sillenite $[1,15,16]$. The two basic building blocks of crystal structure are usually considered to be the $\left(\mathrm{BiO}_{7}\right)$ [11] polyhedrons interconnected in a complex manner and the $\left(\mathrm{MO}_{4}\right)^{4-}$ tetrahedrons situated at the corners and the center of the conventional unit cell The primitive cell of BMO contains 33 atoms, of which the nonequivalent $\mathrm{Bi}$ on Wyckoff position $24 \mathrm{f}$, and $\mathrm{M}$ on position $2 \mathrm{a}[1,15,16]$. In all of our calculations that were performed using the ab-initio total-energy and moleculardynamics program VASP (Vienna ab-initio simulation program) [17-20] that was developed within the density functional theory (DFT), [21] the exchange-correlation energy function is treated within the GGA (generalized gradient approximation) by the density functional of Perdew et al [22]. The potentials used for the GGA calculations take into account the $3 \mathrm{p}^{2} 3 \mathrm{~s}^{2}[\mathrm{Ne}]$ valence electrons of each $\mathrm{Si}-, 3 \mathrm{~d}^{10} 4 \mathrm{~s}^{2} 4 \mathrm{p}^{2}[\mathrm{Ar}$ ] valence electrons od each Ge-, $4 \mathrm{~d}^{2} 4 \mathrm{~s}^{2}$ [Ar] valence electrons of each Ti-, $5 \mathrm{~d}^{10} 6 \mathrm{~s}^{2} 6 \mathrm{p}^{3}[\mathrm{Xe}$ ] valence electrons of each $\mathrm{Bi}$-, and $2 \mathrm{~s}^{2} 2 \mathrm{p}^{4}$ valence electrons of each $\mathrm{O}$-atoms. When including a planewave basis up to a kinetic-energy cutoff equal to $21.6 \mathrm{Ha}$ for all BMO compounds, the properties investigated in this work are well converged. The Brillouin-zone integration was performed using special $\mathrm{k}$ points sampled within the Monkhorst-Pack scheme [23]. We found that a mesh of $5 \times 5 \times 5 \mathrm{k}$ points for all three compounds was required to describe the structural, mechanical, and electronic properties. This k-point mesh guarantees a violation of charge neutrality less than $0.008 \mathrm{e}$. Such a low value is a good indicator for an adequate convergence of the calculations. The elastic constants are calculated by the efficient stress-strain method [14] as implemented in the VASP code. The optical properties were obtained by complex dielectric function $\varepsilon(\omega)=\varepsilon_{1}(\omega)+\mathrm{i} \varepsilon_{2}(\omega)$ where the details explained in Refs [24-26]. We also calculated dependence of the pressure on the electronic and optical properties of BMO up to $25 \mathrm{GPa}$ from the DFT. 


\section{Results and discussion}

\subsection{Structure optimization and elastic properties of $\mathrm{Bi}_{12} \mathrm{MO}_{20}$}

The BMO compounds belong to the sillenite family with the I23 symmetry, and have one molecule with 33 atoms in unit cells. We have made the geometry optimization using the experimental atomic positions and lattice parameters $[1,15,16]$ in the first step of our calculation. The optimized values of the calculated lattice parameter values are in good agreement with the experimental values [1-11].

The calculated elastic constants and acoustic parameters of BMO compounds with the "strain-stress" relationship [27] for I23 symmetry are shown in Tables 1 and 2. Three independent elastic constants for cubic BMOs are calculated. The mechanical stability criteria for cubic BMOs are $\mathrm{C}_{11}>0, \mathrm{C}_{44}>0, \mathrm{C}_{11}>\left|\mathrm{C}_{12}\right|,\left(\mathrm{C}_{11}+\mathrm{C}_{12}\right)>0$. The polycrystalline bulk modulus (B) and the shear modulus $(\mathrm{G})$ are obtained from the Voigt-Reuss-Hill (VRH) approximation [28-30] using the calculated elastic constants. The isotropic shear modulus is $G=\left(G_{V}+G_{R}\right) / 2$. Here, Voigt's shear modulus is $\mathrm{G}_{\mathrm{V}}=\left(\mathrm{C}_{11}-\mathrm{C}_{12}+3 \mathrm{C}_{44}\right) / 5$ while Reuss's shear modulus is $\mathrm{G}_{\mathrm{R}}=5\left(\mathrm{C}_{11}-\mathrm{C}_{12}\right) \mathrm{C}_{44} /\left[4 \mathrm{C}_{44}+3\left(\mathrm{C}_{11}\right.\right.$ $\left.C_{12}\right)$ ]. The bulk modulus for cubic crystals is $B_{R}=B_{V}=\left(C_{11}+2 C_{12}\right) / 3[31,32]$. Poisson's ratio is $\vartheta=1 / 2[\mathrm{~B}-(2 / 3) \mathrm{G}) /(\mathrm{B}+(1 / 3) \mathrm{G})]$. The value of the Poisson's ratio is always 0.1 for covalent materials and 0.25 for ionic materials. Young's modulus is $E=9 \mathrm{~GB} /(\mathrm{G}+3 \mathrm{~B})$. The calculated Young's modulus gives a measure of hardness [33-35]. The Zener anisotropy factor is $\mathrm{A}=2 \mathrm{C}_{11} /\left(\mathrm{C}_{11}-\mathrm{C}_{12}\right)$ [36]. The Zener anisotropy factor is an indicator of the degree of anisotropy in the solid structure. If the $\mathrm{B} / \mathrm{G}$ ratio is less (higher) than 1.75, a material is brittle (ductile) [36]. It is well known that the Debye temperature $\left(\Theta_{\mathrm{D}}\right)$ is a basic parameter associated with many physical properties of materials. The $\Theta_{\mathrm{D}}$ obtained using elastic constants at low temperatures (the vibration excitation at this temperature only originates from the acoustic vibrations) is the same as determined from the specific temperature measurements. In addition, sound velocities $(v t, v 1, v \mathrm{~m})$, and the $\Theta_{\mathrm{D}}$ 's $\left(\nu_{\mathrm{m}}=\left[1 / 3\left(2 / \mathrm{v}_{\mathrm{t}}{ }^{3}+1 / \mathrm{v}_{\mathrm{l}}{ }^{3}\right)\right]^{-1 / 3}, \quad \nu_{\mathrm{l}}=[(3 \mathrm{~B}+4 \mathrm{G}) / 3 \rho]^{1 / 2}, \quad \nu_{\mathrm{t}}=[\mathrm{G} / \rho]^{1 / 2}, \quad\right.$ and $\left.\theta_{\mathrm{D}}=\mathrm{h} / \mathrm{k}[3 \mathrm{n} / 4 \Pi(\mathrm{N} \mathrm{A} \rho / \mathrm{M})]^{1 / 3}\right)[36]$ of the compounds considered are also calculated, and the results are shown in Table 2 . Unfortunately, there are no theoretical and experimental values for comparing the obtained values. The ionic character in atomic bonding from the obtained Poisson's ratio ( $v=0.26$ for all compounds) for the base case can be said to be dominant. The calculated isotropic shear and bulk moduli values for compounds are very close to each other. It can be said to be less compressible materials from the calculated isotropic shear (65.6 for $\mathrm{Bi}_{12} \mathrm{SiO}_{20}$, and 63.3 for $\mathrm{Bi}_{12} \mathrm{GeO}_{20}$ ) and bulk (120.8 for $\mathrm{Bi}_{12} \mathrm{SiO}_{20}, 117.9$ for $\mathrm{Bi}_{12} \mathrm{GeO}_{20}$ ) moduli for these compounds. The Young's modulus (E) is a measure of the stiffness, and if the value of Young's modulus is large, as a result the high modulus of these materials indicates their stiffness. The calculated Young's modulus values for these compounds are 166.5 for $\mathrm{Bi}_{12} \mathrm{SiO}_{20}$, and

Table 1. The calculated elastic constants (in $\mathrm{GPa}$ ), isotropic bulk modulus ( $\mathrm{B}$, in $\mathrm{GPa}$ ), shear modulus $(G$, in $G P a)$, Young's modulus $(E$, in $G P a)$, Poisson's ratio and Zener anisotropy factor for $\mathrm{Bi}_{12} \mathrm{MO}_{20}$ $(\mathrm{M}=\mathrm{Si}$ and $\mathrm{Ge})$.

\begin{tabular}{|c|c|c|c|c|c|c|c|c|c|c|}
\hline Material & Reference & $C_{11}$ & $C_{12}$ & $C_{44}$ & B & G & $E$ & $\vartheta$ & $B / G$ & A \\
\hline $\mathrm{Bi}_{12} \mathrm{SiO}_{20}$ & Present & 212.49 & 74.98 & 63.49 & 120.8 & 65.6 & 166.5 & 0.27 & 1.84 & 0.923 \\
\hline $\mathrm{Bi}_{12} \mathrm{GeO}_{20}$ & Present & 206.69 & 73.57 & 61.19 & 117.9 & 63.3 & 161.1 & 0.27 & 1.86 & 0.919 \\
\hline
\end{tabular}


Table 2. The calculated sound velocities $\left(v_{t}, v_{l}, v_{m}\right)$ and the Debye temperatures for $\mathrm{Bi}_{12} \mathrm{MO}_{20}(\mathrm{M}=\mathrm{Si}$ and $\mathrm{Ge})$.

\begin{tabular}{lccccc}
\hline Material & Reference & $v_{t}(\mathrm{~m} / \mathrm{s})$ & $v_{l}(\mathrm{~m} / \mathrm{s})$ & $v_{m}(\mathrm{~m} / \mathrm{s})$ & $\theta_{\mathrm{D}}(\mathrm{K})$ \\
\hline $\mathrm{Bi}_{12} \mathrm{SiO}_{20}$ & Present & 2737 & 4877 & 3046 & 357 \\
$\mathrm{Bi}_{12} \mathrm{GeO}_{20}$ & Present & 2690 & 4808 & 2994 & 349 \\
\hline
\end{tabular}
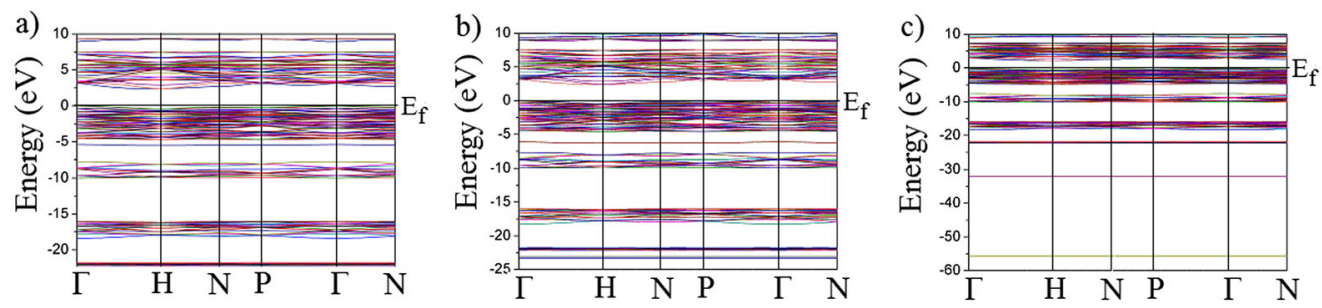

Figure 1. Energy band structure for a) $\mathrm{Bi}_{12} \mathrm{SiO}_{20}$, b) $\mathrm{Bi}_{12} \mathrm{GeO}_{20}$, and c) $\mathrm{Bi}_{12} \mathrm{TiO}_{20}$.

161.1 for $\mathrm{Bi}_{12} \mathrm{GeO}_{20}$. Young's modulus is defined as the ratio of stress and strain, and used to provide a measure of the stiffness of the solid. Here, the highest Young's modulus belongs to BMO compounds. The value of the Poisson's ratio is indicative of the degree of directionality of the covalent bonds. The value of Poisson's ratio is small $(\vartheta=0.1)$ for covalent materials, whereas for ionic materials a typical value is 0.25 [35]. As can be seen in Table 1, the ionic contribution to inter atomic bonding for these compounds is dominant ( $\vartheta=0.27$ for both compounds). The Zener anisotropy factor A obtained as, $\mathrm{A}=2 \mathrm{C}_{44} /\left(\mathrm{C}_{11}-\mathrm{C}_{12}\right)$. The Zener anisotropy factor is an indicator of the degree of anisotropy in the solid structure. For a completely isotropic material, the factor A takes the value of 1 . When the value is smaller or greater than unity, it is a measure of the degree of elastic anisotropy. The calculated Zener anisotropy factor 0.923 and 0.919 for $\mathrm{Bi}_{12} \mathrm{SiO}_{20}$ and $\mathrm{Bi}_{12} \mathrm{GeO}_{20}$, respectively (Table 1), therefore, demonstrates that these materials have very small elastic anisotropy. The Debye temperature and sound velocity calculated for $\mathrm{Bi}_{12} \mathrm{SiO}_{20}$ and $\mathrm{Bi}_{12} \mathrm{GeO}_{20}$ compounds are shown in Table 2 . Usually, the Debye temperature is low for soft materials, but is high for rigid materials. Consequently, these compounds can be called nearly rigid materials.

\subsection{Electronic structure and density of states}

The band structures of BMO compounds along the high symmetry directions " $\mathrm{T} \rightarrow \mathrm{H} \rightarrow$ $\mathrm{N} \rightarrow \mathrm{P} \rightarrow \Gamma \rightarrow \mathrm{N}$ " $[\Gamma=(0,0,0), \mathrm{H}=(1 / 2,-1 / 2,1 / 2), \mathrm{P}=(1 / 3,1 / 4,1 / 4), \mathrm{N}=(0,0,1 / 2)]$ calculated, and have been shown in Figure 1. The calculations show that the valance band maximum and conduction band minimum for $\mathrm{Bi}_{12} \mathrm{SiO}_{20}, \mathrm{Bi}_{12} \mathrm{GeO}_{20}$ and $\mathrm{Bi}_{12} \mathrm{TiO}_{20}$ compounds are between $\Gamma$ and $H$ high symmetry points of the first Brillouin zone $\left(\mathrm{E}_{\mathrm{g}}=\right.$ $2.42 \mathrm{eV}, 2.46 \mathrm{eV}$, and $2.40 \mathrm{eV}$, respectively) and they are in good agreement with the experimental values [7, 9-13]. Therefore, these compounds are piezoelectrics with an indirect band gap. For all calculated compounds we observed the next electronic states: 132 for $\mathrm{Bi}_{12} \mathrm{SiO}_{20}, 157$ for $\mathrm{Bi}_{12} \mathrm{GeO}_{20}$ and 152 for $\mathrm{Bi}_{12} \mathrm{TiO}_{20}$ in the energy region between (-30.0 and 0 ) eV. For $\mathrm{Bi}_{12} \mathrm{SiO}_{20}$ compound, the lowest valance bands, valance bands between $-(30-20) \mathrm{eV}$ and $-(18-12) \mathrm{eV}$, and uppermost occupied valance 
bands are formed by $\mathrm{Bi} 6 \mathrm{p}$ states, the hybridization of $\mathrm{O} 2 \mathrm{~s}-\mathrm{Bi} 6 \mathrm{p}$ states (the $\mathrm{Bi} 6 \mathrm{p}$ states is dominant) and $\mathrm{Si} 2 \mathrm{p}-\mathrm{O} 2 \mathrm{~s}$ states (the $\mathrm{O} 2 \mathrm{~s}$ states is dominant), respectively. For $\mathrm{Bi}_{12} \mathrm{GeO}_{20}$ compound, the lowest valance bands, valance bands between -(30-10) $\mathrm{eV}$, and uppermost occupied valance bands are formed by $\mathrm{Bi} 6 \mathrm{p}$ states, the hybridization of $\mathrm{O} 2 \mathrm{~s}-\mathrm{Bi} 6 \mathrm{p}$ states (the $\mathrm{Bi} 6 \mathrm{p}$ states is dominant). For the $\mathrm{Bi}_{12} \mathrm{TiO}_{20}$ compound, the lowest valance bands, valance bands between $-(40-15) \mathrm{eV}$, and uppermost occupied valance bands are formed by Ti 6 s states, Ti $6 \mathrm{p}$ states, Bi $6 \mathrm{p}$ states and the hybridization of $\mathrm{Bi} 6 \mathrm{p}-\mathrm{O} 2 \mathrm{~s}$ states (the $\mathrm{Bi} 6 \mathrm{p}$ states is dominant). The highest valence bands for all investigated compounds are formed by $\mathrm{O} 2 \mathrm{p}$ states and hybridization of $\mathrm{O} 2 \mathrm{p}-\mathrm{M}$ and ( $\mathrm{Si}, \mathrm{Ge}$, and $\mathrm{Ti}$ ) states (the $\mathrm{O} 2 \mathrm{p}$ states is dominant). The lowest unoccupied conduction bands above the Fermi energy for the three compounds are formed by the hybridization of $\mathrm{p}$ and $\mathrm{d}$ states, but $\mathrm{d}$ states is dominant. The pressure coefficient of $\mathrm{Eg}$ for investigated BMO appr. is $2 \mathrm{meV} / \mathrm{kbar}$.

\subsection{Optical properties}

We have first calculated the real and imaginary part of $\varepsilon(\omega)=\varepsilon_{1}(\omega)$-i $\varepsilon_{2}(\omega)$ complex dielectric function using the Kramers-Kroning relations. The other optical functions such as energy-loss function, have been calculated with the help of the real and imaginary part of dielectric function for these compounds. The energy values of $\varepsilon_{1}$ that decreasing $\left(\mathrm{d} \varepsilon_{1}\right) /(\mathrm{dE}<0)$ and increasing $\left(\mathrm{d} \varepsilon_{1}\right) /(\mathrm{dE}>0)$ are zero are $6.66 \mathrm{eV}(9.84 \mathrm{eV})$, $10.54 \mathrm{eV}(10.61 \mathrm{eV})$ and $13.71 \mathrm{eV}(19.91 \mathrm{eV})$ for $\mathrm{Bi}_{12} \mathrm{SiO}_{20}$ compound, $6.69 \mathrm{eV}(9.88 \mathrm{eV})$, $10.28 \mathrm{eV}(10.76 \mathrm{eV})$ and $13.63 \mathrm{eV}(19.85 \mathrm{eV})$ for $\mathrm{Bi}_{12} \mathrm{GeO}_{20}$ compound, and $6.72 \mathrm{eV}$ $(10.72 \mathrm{eV})$, and $13.55 \mathrm{eV}(20.16 \mathrm{eV})$ for $\mathrm{Bi}_{12} \mathrm{TiO}_{20}$ compound. These values that the $\varepsilon_{1}$ are zero are points reduced of the reflections, and show that the polarization disappears. The maximum of main peak values of $\varepsilon_{2}$ are $4.73 \mathrm{eV}, 6.28 \mathrm{eV}, 10.45 \mathrm{eV}, 13.71 \mathrm{eV}$, $27.10 \mathrm{eV}, 27.58 \mathrm{eV}$ and $29.32 \mathrm{eV}$ for $\mathrm{Bi}_{12} \mathrm{SiO}_{20}$ compound, $4.86 \mathrm{eV}, 6.21 \mathrm{eV}, 10.20 \mathrm{eV}$, $13.35 \mathrm{eV}, 27.127 .66 \mathrm{eV}$, and $29.34 \mathrm{eV}$ for $\mathrm{Bi}_{12} \mathrm{GeO}_{20}$ compound, and $4.84 \mathrm{eV}, 6.25 \mathrm{eV}$, $10.14 \mathrm{eV}, 12.03 \mathrm{eV}, 13.68 \mathrm{eV}, 25.47 \mathrm{eV} 26.60 \mathrm{eV}$ and $29.40 \mathrm{eV}$ for $\mathrm{Bi}_{12} \mathrm{TiO}_{20}$ compound. These values show how much the electromagnetic wave polarizes the system, and corresponds to the electronic transitions from the valance band to the conduction band. The pressure dependence on optical spectra only shifted maximum of main peaks of $\varepsilon_{2}$ to higher energy region but don't change the structure of optical spectra in this region $(2-30 \mathrm{eV})$. This energy region corresponds to the region beginning of the transition between the bands. The $2.0-15.0 \mathrm{eV}$ energy region for these compounds is the region where the transitions between the bands are very intense. The energy region above $15 \mathrm{eV}$ also corresponds to the collective vibration of valance electrons. This energy region defined as plasma oscillations is described by the energy loss function. The values of valence electrons plasma oscillation energy for $\mathrm{Bi}_{12} \mathrm{SiO}_{20}, \mathrm{Bi}_{12} \mathrm{GeO}_{20}$, and $\mathrm{Bi}_{12} \mathrm{TiO}_{20}$ compounds are $20.45 \mathrm{eV}, 20.41 \mathrm{eV}$, and $19.60 \mathrm{eV}$, respectively.

\section{Conclusions}

We have performed the structural, mechanical, electronic, and optical properties of the BMO compounds using density functional theory within the GGA approximation. The 
lattice parameters obtained as a result of geometric optimization are in good agreement with the experimental values. Because the calculated shear and bulk modules obtained by using the calculated elastic constants are very close to each other, $\mathrm{Bi}_{12} \mathrm{SiO}_{20}$ and $\mathrm{Bi}_{12} \mathrm{GeO}_{20}$ compounds are less compressible materials. Since the calculated Young's modulus of the $\mathrm{Bi}_{12} \mathrm{SiO}_{20}$ compound is larger than the $\mathrm{Bi}_{12} \mathrm{GeO}_{20}$ compound, it can be said that the $\mathrm{Bi}_{12} \mathrm{SiO}_{20}$ compound is harder than the $\mathrm{Bi}_{12} \mathrm{GeO}_{20}$ compound. In both compounds, ionic character is dominant and these compounds have small elastic anisotropy. In the calculation of the calculated electronic band structure, BMO compounds are found as indirect band structured semiconductors in nature. The optical constants such as real and imaginary part of dielectric function, energy-loss function for these compounds were calculated.

\section{References}

[1] L. Wiehl et al., Structural compression and vibrational properties of $\mathrm{Bi}_{12} \mathrm{SiO}_{20}$ sillenite from experiment and theory, J. Phys: Condens. Matter. 22, 505401 (2010). DOI: 10.1088/ 0953-8984/22/50/505401.

[2] H. S. Horowitz et al., Solution synthesis and characterization of sillenite phases, $\mathrm{Bi}_{24} \mathrm{M}_{2} \mathrm{O}_{40}(\mathrm{M}=\mathrm{Si}, \mathrm{Ge}, \mathrm{V}, \mathrm{As}, \mathrm{P})$, Solid State Lonics. 32 (33), 678 (1989). DOI: 10.1016/ 0167-2738(89)90344-5.

[3] R. Rao et al., High pressure stability of bismuth sillenite: A Raman spectroscopic and xray diffraction study, J. Appl. Phys. 108 (8), 083508 (2010). DOI: 10.1063/1.3496659.

[4] H. F. McMurdie et al., Standard x-ray diffraction powder patterns from the JCPDS research associateship, Powder Diffr. 1 (3), 265 (1986). DOI: 10.1017/S0885715600011829.

[5] T. Takamori, The system $\mathrm{Bi}_{2} \mathrm{O}_{3}-\mathrm{SiO}_{2}$, J. Am. Ceramic Soc. 73 (1), 158 (1990). DOI: 10. 1111/j.1151-2916.1990.tb05112.x.

[6] Z. Z. Lazarevic' et al., Determination of magneto-optical quality and refractive index of bismuth germanium oxide single crystals grown by Czochralski technique, Optical Mater. 34, 1849 (2012).

[7] Z. Wan, and G. Zhang, Controlled synthesis and visible light photocatalytic activity of $\mathrm{Bi}_{12} \mathrm{GeO}_{20}$ uniform microcrystals, Sci. Rep. 4 (1), 6298 (2015). DOI: 10.1038/srep06298.

[8] S. M. Efendiev et al., Crystal structure of bismuth titanium oxide $\mathrm{Bi}_{12} \mathrm{TiO}_{20}$, Phys. Stat. Sol. (a). 74 (1), K17 (1982). DOI: 10.1002/pssa.2210740148.

[9] W. F. Yao et al., Photocatalytic property of bismuth titanate $\mathrm{Bi}_{12} \mathrm{TiO}_{20}$ crystals, Appl. Catal. A: General. 243, 185 (2003).

[10] N. Thanabodeekij et al., $\mathrm{Bi}_{12} \mathrm{TiO}_{20}$ synthesized directly from bismuth (III) nitrate pentahydrate and titanium glycolate and its activity, Powder Techn. 160 (3), 203 (2005). DOI: 10. 1016/j.powtec.2005.08.015.

[11] J. Zhou et al., Preparation and characterization of polycrystalline bismuth titanate $\mathrm{Bi}_{12} \mathrm{TiO}_{20}$ and its photocatalytic properties under visible light irradiation, Ind. Eng. Chem. Res. 46 (3), 745 (2007). DOI: 10.1021/ie0613220.

[12] S. Xu et al., Photocatalytic properties of bismuth titanate $\mathrm{Bi}_{12} \mathrm{TiO}_{20}$ prepared by coprecipitation processing, Mater. Sci. Eng. B. 137 (1-3), 108 (2007). DOI: 10.1016/j.mseb. 2006.10.019.

[13] W. Wei et al., First-principles characterization of Bi-based photocatalysts: $\mathrm{Bi}_{12} \mathrm{TiO}_{20}$, $\mathrm{Bi}_{2} \mathrm{Ti}_{2} \mathrm{O}_{7}$, and $\mathrm{Bi}_{4} \mathrm{Ti}_{3} \mathrm{O}_{12}$, J. Phys. Chem. C. 113 (14), 5658 (2009). DOI: 10.1021/jp810344e.

[14] D. A. Papaconstantopoulos, and D. J. Singh, Calculations of elastic moduli from first principles, in Statistics and Dynamics of Alloy Phase Transformations, edited by P. E. A. Turchi, A. Gonis (NATO ASI Ser., 1993), vol. 319.

[15] A. V. Firsov et al., X-ray-diffraction investigation and dielectric-properties of $\mathrm{Sb}_{4} \mathrm{Ge}_{3} \mathrm{O}_{12}$ single-crystals and phases of the $\mathrm{Bi}_{2} \mathrm{O}_{3}-\mathrm{GeO}_{2}\left(\mathrm{SiO}_{2}\right)$ systems, Inorg. Mater. 21, 378 (1985). 
[16] V. V. Volkov et al., Russian J Inorg. Chem. 34, 1787 (1989).

[17] G. Kresse, and J. Hafner, Ab initio molecular dynamics for liquid metals, Phys. Rev. B. 47 (1), 558 (1993). DOI: 10.1103/PhysRevB.47.558.

[18] G. Kresse, and J. Furthmüller, Ab-initio total energy calculations for metals and semiconductors using a plane-wave basis set, Comput. Mater. Sci. 6 (1), 15 (1996). DOI: 10.1016/ 0927-0256(96)00008-0.

[19] G. Kresse, and D. Joubert. From ultrasoft pseudopotentials to the projector augmentedwave method, Phys. Rev. B. 59 (3), 1758 (1999). DOI: 10.1103/PhysRevB.59.1758.

[20] G. Kresse, and J. Furthmüller, Efficient iterative schemes for ab initio total- energy calculations using a plane-wave basis set, Phys. Rev. B. 54 (16), 11169 (1996). DOI: 10.1103/ PhysRevB.54.11169.

[21] P. Hohenberg, and W. Kohn, Inhomogeneous electron gas, Phys. Rev. 136 (3B), B864 (1964). DOI: 10.1103/PhysRev.136.B864.

[22] J. P. Perdew et al., Generalized gradient approximation made simple, Phys. Rev. Lett. 77 (18), 3865 (1996). DOI: 10.1103/PhysRevLett.77.3865.

[23] H. J. Monkhorst, and J. D. Pack, Special points for Brillouin-zone integrations, Phys. Rev. B. 13 (12), 5188 (1976). DOI: 10.1103/PhysRevB.13.5188.

[24] H. R. Philipp, and H. Ehrenreich, Optical properties of semiconductors, Phys. Rev. 129 (4), 1550 (1963). DOI: 10.1103/PhysRev.129.1550.

[25] Z. H. Levine, and D. C. Allan, Linear optical response in silicon and germanium including self-energy effects, Phys. Rev. Lett. 63 (16), 1719 (1989). DOI: 10.1103/PhysRevLett.63.1719.

[26] O. V. Kovalev, Representations of the Crystallographic Space Groups. Irreducible Representations Induced Representations and Corepresentations (Gordon and Breach, Amsterdam, 1965).

[27] Y. Le Page, and P. Saxe, Symmetry-general least-squares extraction of elastic coefficients from ab initio total energy, Phys. Rev. B. 63 (17), 174103 (2001). DOI: 10.1103/PhysRevB.63.174103.

[28] W. Voigt, Lehrbuch der Kristallphysik (Teubner, Leipzig 1928), p. 962.

[29] A. Reuss, Berechnung der Fießgrenze von Mischkristallen auf Grund der Plastizitätsbedingung für Einkristalle, $Z$ Angew. Math. Mech. 9 (1), 49 (1929). DOI: 10. 1002/zamm.19290090104.

[30] R. Hill, The elastic behavior of crystalline aggregate, Proc. Phys. Soc. A. 65 (5), 349 (1952). DOI: $10.1088 / 0370-1298 / 65 / 5 / 307$.

[31] J. Hanies et al., Synthesis and design of super hard materials, Annu. Rev. Mater. Res. 31, 1 (2001).

[32] Z. J. Wu et al., Crystal structure and elastic properties of superhard $\operatorname{IrN}_{2}$ and $\operatorname{IrN}_{3}$ from first principles, Phys. Rev. B. 76 (5), 054115 (2007). DOI: 10.1103/PhysRevB.76.059904.

[33] K. B. Panda, and K. S. R. Chandran, First principles determination of elastic constants and chemical bonding of titanium boride $(\mathrm{TiB})$ on the basis of density functional theory, Acta Mater. 54 (6), 1641 (2006). DOI: 10.1016/j.actamat.2005.12.003.

[34] P. Ravindran et al., Density functional theory for calculation of elastic properties of orthorhombic crystals: Application to TiSi 2 , J. Appl. Phys. 84 (9), 4891 (1998). DOI: 10.1063/1.368733.

[35] V. V. Bannikov et. al., Electronic structure, chemical bonding and elastic properties of the first thorium-containing nitride perovskite $\mathrm{TaThN}_{3}$, Phys. Stat. Sol. (Rrl). 3, 89 (2007). DOI: $10.1002 /$ pssr.200600116.

[36] E. Schreiber et al., Elastic constants and their measurements (McGraw-Hill, New York 1973). 